\title{
Bone status in cystic fibrosis
}

\author{
M Sood, G Hambleton, M Super, W D Fraser, J E Adams, M Z Mughal
}

The Cystic Fibrosis

Unit, Royal

Manchester Children's

Hospital, Hospital

Road, Manchester

M27 4HA, UK

$M$ Sood

G Hambleton

M Super

Department of Clinical Chemistry, Royal

Liverpool University

Hospital, Liverpool

L69 3GA, UK

W D Fraser

Clinical Radiology,

Imaging Sciences, and

Biomedical

Engineering,

University of

Manchester, Oxford

Road, Manchester

M13 9PT, UK

J E Adams

Department of

Paediatric Medicine,

Saint Mary's Hospital

for Women \&

Children, Hathersage

Road, Manchester

M13 0JH, UK

M Z Mughal

Correspondence to:

Dr Mughal

zulf.mughal@man.ac.uk

Accepted 29 January 2001

\begin{abstract}
Aim-To investigate bone mineral status of children with cystic fibrosis (CF).

Methods-In 29 children with CF and 49 matched controls, bone mineral content (BMC), projected bone area (BA), and areal bone mineral density (BMD) of the whole body, total hip, and lumbar spine (L1-L4) were measured using dual energy $x$ ray absorptiometry. The BMC values at each site were adjusted for $B A$, height, and weight. At the lumbar spine, the bone mineral apparent density (BMAD) was calculated by dividing the BMC by the estimated volume, derived from BA. Vertebral (T12-L3) trabecular bone mineral density (vTBMD) was measured using quantitative computed tomography in children with CF. Calcaneal broadband ultrasound attenuation (BUA) was measured in CF patients and controls using quantitative ultrasound. The disease severity of CF children was evaluated by the Shwachman-Kulczycki (SK) score.
\end{abstract}

Results-The mean BUA, whole body and regional $\mathrm{BA}$, adjusted $\mathrm{BMC}$, and areal BMD of children with CF were not different from those of controls. The mean BMAD of the lumbar spine was reduced in CF patients compared with controls, whereas the mean vTBMD standard deviation scores were significantly higher in CF patients. The median SK score of the CF group was 81 (range 42-100), indicating that as a group our CF patient population had relatively mild disease.

Conclusion-The normal vertebral BMC, decreased BMAD, and higher vTBMD suggests that the vertebral cortical thickness or density might be reduced in CF subjects. The overall bone mineral status of CF children with relatively mild disease was not different from size matched controls.

(Arch Dis Child 2001;84:516-520)

Keywords: cystic fibrosis; bone mineral status

Improvements in nutritional and pulmonary management of cystic fibrosis (CF) have resulted in improved survival, ${ }^{1}$ with many patients surviving into adulthood. ${ }^{2}$ Atraumatic fractures of the axial and appendicular skeleton are becoming an important health problem in adolescents and adults with $\mathrm{CF}^{3-5}$ Thoracic kyphosis resulting from wedge fractures of vertebral bodies has also been reported in this age group. ${ }^{3}$ Factors responsible for bone fragility in CF subjects include small bone size, ${ }^{6}$ inadequate gain in bone mass during growth and puberty, ${ }^{7}$ and excessive bone loss. ${ }^{8}$ Epidemiological studies in adults have shown that bone mineral content (BMC) and density (BMD) are important predictors of an individual's fracture risk. ${ }^{9}$ Reduced BMC and BMD have been reported both in children and adults with CF. Linear BMD of the forearm bones measured using single photon absorptiometry was found to be decreased in adolescents and adults. ${ }^{1011}$ However, this technique did not permit assessment of BMC or BMD at the spine or the total hip. Recent studies using dual energy $x$ ray absorptiometry (DXA) to assess bone mass and areal BMD $\left(\mathrm{g} / \mathrm{cm}^{2}\right)$ in the spine and proximal femur in children have yielded conflicting results. Henderson and Madsen $^{12}$ and Bhudhikanok and colleagues ${ }^{7}{ }^{13}$ found significant reduction in BMD at the lumbar spine and proximal femur in $\mathrm{CF}$ patients. However, using gender, age, and nutritional status matched controls, Salamoni and colleagues ${ }^{14}$ reported normal whole body and lumbar spine BMD in children with CF, whereas Laursen and colleagues ${ }^{6}$ found shorter and narrower bones, but increased size corrected $\mathrm{BMC}$, in children and teenagers with CF. Bone mineral density $\left(\mathrm{g} / \mathrm{cm}^{3}\right)$ of the trabecular component of the vertebral bodies measured by quantitative computed tomography (QCT) has been reported to be decreased in children and adults with $\mathrm{CF} \cdot{ }^{15-17}$

None of these techniques measure the bone structure, which is an important determinant of bone strength. ${ }^{18}$ Broadband ultrasound attenuation (BUA) at the calcaneum measured by quantitative ultrasound (QUS) has been shown to predict fracture risk in elderly women independently of bone mineral density. ${ }^{19}$ It has been suggested that ultrasonic attenuation through bone reflects both density and structural properties. ${ }^{18}$ In this cross sectional study, we measured the calcaneal BUA and BMC in grams, projected bone area (BA) in $\mathrm{cm}^{2}$, and areal bone mineral density (BMD) in $\mathrm{g} / \mathrm{cm}^{2}$ of the whole body, total hip, and lumbar spine (L1-L4) in children with CF and intentionally age, gender, pubertal stage, height, and weight matched controls. In CF children, we selectively measured the vertebral (T12-L3) trabecular bone mineral density (vTBMD) using QCT. We also measured the nutritional parameters relevant to bone mineralisation and estimated weight bearing physical activity. We hypothesised that as a group children with CF would have reduced:

- vTBMD standard deviation scores

- calcaneal BUA, and whole body, total hip, and lumbar spine BMC and BMD compared to intentionally age, gender, pubertal stage, height, and weight matched controls. 


\section{Subjects and methods}

Eighty five children between 5 and 16 years of age attending the regional paediatric CF clinic were invited to participate in the study. Twenty nine children (12 girls and 17 boys) agreed to participate in the study. Children with spinal deformities, immobilising disease, or major surgery in the previous 12 months were excluded. The diagnosis of $\mathrm{CF}$ had been confirmed by sweat test and by CF gene mutation analysis. Nineteen patients were homozygous for delta F508 mutation and eight had one delta F508 and one other known CF mutation; gene status in two patients was unknown. All patients were on unrestricted diet and taking Ketovite multivitamin liquid and tablets (Paines \& Byrne, West Byfleet, Surrey, UK) and pancreatic enzyme supplements. Fifteen children were receiving oral calorie supplements: Polycal (Nutricia Clinical Care, Trowbridge, Wiltshire, UK) in five; Fresubin (Fresenius Ltd, Warrington, UK) in three; Fortijuce (Nutricia Clinical Care, Trowbridge, Wiltshire, UK) in two; and Scandishake (Scientific Hospital Supplies, Liverpool, UK) in five.

Parents of 385 local school children who agreed to allow their children to participate in this study were asked to complete a questionnaire with details of previous medical history. Children with a history of medical problems known to effect bone mineralisation, and those who had been treated with oral or inhaled corticosteroids were excluded. For each CF patient we aimed to recruit two control subjects matched for age, gender, pubertal stage, height, and weight. Matching criteria for age was \pm 12 months, height $\pm 10 \mathrm{~cm}$, and weight $\pm 5 \mathrm{~kg}$. However, one of the controls was $6.1 \mathrm{~kg}$ heavier than the CF subject. Twenty one CF patients had two control subjects each, and in eight patients only one matched control could be recruited. Written consent was obtained from the parents or guardians of all the children. The study was approved by the Salford Research Ethics Committee.

Weight was measured to the nearest $0.25 \mathrm{~kg}$ using a digital electronic scale. Height was measured to the nearest millimetre using a portable stadiometer (Karrimetre Mark III, Raven Equipment Ltd). Body mass index $\left(\mathrm{BMI}=\right.$ weight $/$ height $\left.^{2}\right)$ was calculated from height and weight. Weight, height, and BMI standard deviation (SD) score were calculated using the 1990 UK normative data supplied by the Child Growth Foundation. ${ }^{20}$ Children with $\mathrm{CF}$ underwent full pubertal assessment. ${ }^{21}$ In controls puberty was assessed by direct assessment ${ }^{21}$ or by using the previously validated self assessment method. ${ }^{22}$

Disease severity was evaluated by the Shwachman-Kulczycki (SK) score. $^{23}$ Forced vital capacity (FVC) and forced expiratory volume in one second $\left(\mathrm{FEV}_{1}\right)$ were measured in the CF subjects and expressed as percentage of expected for height. ${ }^{24}$ Three patients had received oral corticosteroid therapy for less than three weeks and 18 had been treated with inhaled corticosteroids.
Three day food diaries were completed and returned by 21 children with CF. Daily calcium intake was estimated using McCance and Widdowson's composition of food tables ${ }^{25}$ and Microdiet software (Salford University System, Salford, UK). A previously validated questionnaire ${ }^{26}$ was used to estimate the number of hours of weight bearing physical activity per week in CF children and controls.

BMC in grams and the projected posteroanterior bone area (BA) in $\mathrm{cm}^{2}$ were measured using the Hologic QDR 4500 Acclaim fan beam DXA scanner (Hologic Inc., Bedford, Massachusetts, USA), using the V8.24a:3 software for the whole body, the total hip, and the lumbar spine (L1-L4). The areal BMD in $\mathrm{g} / \mathrm{cm}^{2}$ (BMD) was calculated by dividing BMC in grams by the projected $\mathrm{BA}$ in $\mathrm{cm}^{2}$. The bone mineral apparent density (BMAD) of the lumbar spine in $\mathrm{g} / \mathrm{cm}^{3}$ was calculated by dividing the total vertebral BMC in grams by the estimated volume in $\mathrm{cm}^{3}$, derived from $\mathrm{BA}^{1.5}$, as described by Carter and colleagues. ${ }^{27}$ The whole body scans were performed with subjects lying supine and wearing T-shirt and shorts. The in vivo coefficient of variation (CV) for whole body BMC for adults is $0.92 \%$; and for $\mathrm{BMD}$ of lumbar spine $1.09 \%$ and for total hip $1.26 \%$. The total effective ionising radiation dose for all the DXA scans ranged between 5.6 and $10.8 \mu \mathrm{Sv}$, depending on the size of the subject, and whether the ovaries were included in the scans.

The vTBMD in $\mathrm{mg} / \mathrm{cm}^{3}$ was measured through the mid plane of T12-L3 vertebral bodies by QCT using a Philips Tomoscan SR 4000 scanner (Philips Medical Imaging, Best, Holland), by single energy, low dose scanning technique $(120 \mathrm{Kv}, 50 \mathrm{~mA}, 2$ second scan time). The mean vTBMD in $\mathrm{mg} / \mathrm{cm}^{3}$ was expressed as mineral equivalents of $\mathrm{K}_{2} \mathrm{HPO}_{4}$ in water. The effective ionising radiation dose for this measurement is $100 \mu \mathrm{Sv}$ and the precision in our unit for healthy adults is $1.3 \%$. The vTBMD values were transformed into SD score using the published values in children from the USA. ${ }^{28}$

The BUA, which reflects the frequency dependence of ultrasound attenuation in the frequency range $200-600 \mathrm{kHz}$, was measured in triplicate at the left calcaneum using the Paediatric Contact Ultrasound Bone Analyser (McCue Ultrasonic Limited, Winchester, UK) system as described previously. ${ }^{29}$ BUA values of CF patients were converted to SD scores using published normative values for UK children. ${ }^{30}$

Non-fasting blood samples were obtained only from CF subjects, between 9 and $11 \mathrm{am}$, for analysis of serum calcium, phosphate, alkaline phosphate, alanine transaminase, and albumin using routine biochemical methods. Serum parathyroid hormone (PTH) concentration was measured using a two site chemiluminance method (Chiron Diagnostic Ltd, Halstead, UK). The normal range in adults for this assay is $11-54 \mathrm{pg} / \mathrm{ml}$, the minimal detectable concentration $1.4 \mathrm{pg} / \mathrm{ml}$, with inter- and intraassay coefficient of variation of less than $10 \%$. 
Table 1 Age, anthropometry, and clinical characteristics of children with cystic fibrosis and controls

\begin{tabular}{lcll}
\hline & Patient $(n=29)$ & $\begin{array}{l}\text { Controls }(n=21 \text { pairs } \\
\text { and 8 singletons) }\end{array}$ \\
\hline Age (y) & $10.08(3.22)$ & $10.00(3.19)$ \\
Height (cm) & $136.78(18.11)$ & $136.81(18.47)$ \\
Height SDS & $-0.55(0.93)$ & $-0.47(0.91)$ \\
Weight & $30.10(14.46)$ & $33.12(12.39)$ \\
Weight SDS & $-0.478(1.08)$ & $-0.386(0.84)$ \\
BMI & $15.20(4.15$ & $16.99(2.02)$ \\
BMI SDS & $-0.185(1.08)$ & $-0.142(0.714)$ \\
\hline
\end{tabular}

The data are expressed as mean $( \pm 1 \mathrm{SD})$.

Serum 25-hydroxyvitamin D (25-OHD) concentration was estimated using the ${ }^{125} \mathrm{I}$ radioimmunoassay kit (Diasorin Corp., Minnesota, USA). The minimum detectable concentration with this method is $5 \mathrm{nmol} / \mathrm{l}$, inter- and intra-assay coefficient of variation less than $10 \%$, and adult reference range $22-117 \mathrm{nmol} / 1$. Serum 1,25-dihyroxyvitamin $\mathrm{D}\left(1,25(\mathrm{OH})_{2} \mathrm{D}\right)$ concentration was estimated using the IDS gamma-B 1,25D kit (Diasorin Corp., Minnesota, USA); the inter- and intra-assay coefficient of variation for this technique is less than $10 \%,{ }^{31}$ and adult reference range $54-140$ $\mathrm{pmol} / 1$.

\section{STATISTICAL ANALYSIS}

The statistical analyses were performed using the SPSS software, version 6.1 for Windows (SPSS Inc., Chicago, Illinois, USA). The symmetrically distributed data are expressed as mean $( \pm 1$ SD) where appropriate. Those variables that showed evidence of being asymmetric are presented as median (range). Where there were two controls, average value of the variable was calculated and paired Student's $t$ test used to compare the values of the variables in the two groups. Variables which were notably asymmetric were compared using the Wilcoxon test for two related samples. A single

Table 2 Mean $( \pm 1$ SD) values for DXA measured whole body, total hip, and lumbar spine $B M C, B A, B M D, B M C$ adjusted for bone area, height, and weight; lumbar spine BMAD; calcaneal BUA, BUA adjusted for height and weight, and BUA SD score. Mean values for $v T B M D$ and $v T B M D S D$ scores for children with $C F$ are also shown

\begin{tabular}{|c|c|c|c|}
\hline & CF patients & Controls & $\begin{array}{l}95 \% \text { CI of } \\
\text { the difference }\end{array}$ \\
\hline $\begin{array}{l}\text { Lumbar spine } \\
\text { BA }\left(\mathrm{cm}^{2}\right) \\
\text { BMC }(\mathrm{g}) \\
\text { Adjusted BMC }(\mathrm{SE}) \\
\text { BMD }\left(\mathrm{g} / \mathrm{cm}^{2}\right) \\
\text { Bone volume }\left(\mathrm{cm}^{3}\right) \\
\text { BMAD }\left(\mathrm{g} / \mathrm{cm}^{3}\right) \\
\text { vTBMD }\left(\mathrm{mg} / \mathrm{cm}^{3}\right) \\
\text { vTBMD SD score }\end{array}$ & $\begin{aligned} \mathrm{n}=29 & \\
40.67 & (10.27) \\
28.37 & (12.26) \\
27.05 & (1.01) \\
0.68 & (0.14) \\
265.15 & (98.21) \\
0.11 & (0.02) \\
179.42 & (20.75) \\
0.30 & (0.51)^{\star}\end{aligned}$ & $\begin{array}{c}\mathrm{n}=21 \text { pairs and } 8 \\
38.07(11.22) \\
28.39(13.04) \\
28.82(0.76) \\
0.71(0.12) \\
242.70(109.67) \\
0.12(0.01)^{\star} \\
\text { ND } \\
\text { ND }\end{array}$ & $\begin{array}{l}\text { gletons } \\
-0.499 \text { to } 5.651 \\
-2.430 \text { to } 2.389 \\
-4.33 \text { to } 0.791 \\
-0.071 \text { to } 0.002 \\
-6.667 \text { to } 51.575 \\
-0.018 \text { to }-0.003\end{array}$ \\
\hline $\begin{array}{l}\text { Whole body } \\
\text { BMC (kg) } \\
\text { Adjusted BMC (SE) } \\
\text { BA }\left(\mathrm{cm}^{2}\right) \\
\text { BMD }\left(\mathrm{g} / \mathrm{cm}^{2}\right)\end{array}$ & $\begin{aligned} \mathrm{n}=28 & \\
1.25 & (0.52) \\
1.26 & (0.03) \\
1559.11 & (403.87) \\
0.78 & (0.13)\end{aligned}$ & $\begin{array}{c}\mathrm{n}=20 \text { pairs and } 8 \\
1.31(0.51) \\
1.30(0.18) \\
1772.84(858.27) \\
0.79(0.10)\end{array}$ & $\begin{array}{l}\text { gletons } \\
-0.137 \text { to } 0.018 \\
-0.10 \text { to }-0.002 \\
-516.32 \text { to } 88.85 \\
-0.047 \text { to } 0.020\end{array}$ \\
\hline $\begin{array}{l}\text { Total hip } \\
\text { BMC (g) } \\
\text { Adjusted BMC (SE) } \\
\text { BA }\left(\mathrm{cm}^{2}\right) \\
\text { BMD }\left(\mathrm{g} / \mathrm{cm}^{2}\right)\end{array}$ & $\begin{aligned} \mathrm{n}=29 & \\
16.69 & (8.24) \\
18.16 & (0.45) \\
24.14 & (8.01) \\
0.72 & (0.13)\end{aligned}$ & $\begin{array}{c}\mathrm{n}=21 \text { pairs and } 8 \\
18.91(9.09)^{\star} \\
18.17(0.33) \\
24.34(8.10) \\
0.74(0.12)\end{array}$ & $\begin{array}{l}\text { gletons } \\
-3.849 \text { to } 0.604 \\
-1.15 \text { to } 1.13 \\
-0.870 \text { to } 0.476 \\
-0.058 \text { to } 0.006\end{array}$ \\
\hline $\begin{array}{l}\text { Calcaneal } \\
\text { BUA (dB/MHz) } \\
\text { BUA SD score } \\
\text { Adjusted BUA }\end{array}$ & $\begin{array}{l}\mathrm{n}=29 \\
57.69(25.74) \\
-0.002(1.63) \\
57.87(3.22)\end{array}$ & $\begin{array}{c}\mathrm{n}=18 \text { pairs and } 1 \\
54.18(23.30) \\
-0.02(1.27) \\
58.08(2.48)\end{array}$ & $\begin{array}{l}\text { agletons } \\
-5.696 \text { to } 12.724 \\
-0.649 \text { to } 0.677 \\
-8.32 \text { to } 7.89\end{array}$ \\
\hline
\end{tabular}

group Student's $t$ test was used to determine whether vTBMD SD score data of the CF patients was significantly different from zero. Calcaneal BUA and BMC values at the lumbar spine, whole body, and total hip were compared with those of the control group, after correcting for differences in age, weight, and height by means of covariant analysis. Linear regression analysis was used to study the relation between measures of $\mathrm{BMC}, \mathrm{BMD}$, vTBMD BUA, and indices of disease severity.

\section{Results}

Table 1 summarises the clinical characteristics of patients with cystic fibrosis and controls. Among the CF subjects, 11 boys and five girls were prepubertal, one boy and two girls were in Tanner stage 2, two boys and three girls in stage 3 , and two boys and one girl in stage 4 of pubertal development. The median SK score of the CF group was 81 (range 42-100) indicating that, as a group, our CF patient population had relatively mild disease. The mean (SD) $\mathrm{FEV}_{1}$ and FVC expressed as percentage predicted for height were $77.00 \%$ (20.27) and 88.93\% (19.66) respectively. ${ }^{24}$

The dietary calcium intake for all but four CF patients was above the recommended nutrient intake for age and gender (data not shown). Exercise questionnaires were returned by 24 children with $\mathrm{CF}$ and 34 controls. The median (range) weekly duration of weight bearing physical activity in CF subjects was 8.7 hours (1.5-38.5 hours) compared to 4.75 hours $(0-28$ hours $)$ in controls $(\mathrm{p}=0.07)$.

Serum calcium concentration, corrected for albumin, was below the lower end of the normal range of $2.25 \mathrm{mmol} / 1$ in four patients. Serum phosphate, alkaline phosphatase, alanine transferase, and albumin concentrations were within the normal range for age in all patients. The median serum concentration of 25-OHD (marker of individual's vitamin D status) was $37.0 \mathrm{nmol} / 1$ (18.0-68.0); only one patient had serum 25-OHD concentration below the normal range $(22-117 \mathrm{nmol} / \mathrm{l})$. The median serum $1,25(\mathrm{OH})_{2} \mathrm{D}$ concentration (the biologically active form of vitamin $\mathrm{D}$ ) for the CF patients was $94.5 \mathrm{pmol} / 1$ (54.0-140.0); the concentrations were within the normal adult range $(48-110 \mathrm{pmol} / \mathrm{l})$ for all patients. Serum PTH concentration was within the normal range in all patients. Table 2 shows mean calcaneal BUA, vTBMD, and DXA measured whole body and regional bone mineral content, size, and density data. The BA, areal BMD, and adjusted BMC of whole body, lumbar spine, and total hip were not different between the two groups. The CF patients had similar vertebral BMC, non-significantly larger bone volume, and lower $\mathrm{BMAD}$, compared to size matched controls. In contrast, the mean vTBMD SD score was significantly higher in the CF patients compared to the North American normative group. ${ }^{29}$ The calcaneal BUA adjusted for height and weight and calcaneal BUA SD were not different between the CF patients and matched controls (table 2).

As shown in table 3, age, weight, height, and $\mathrm{BMI}$ correlated with BMC, areal BMD, BUA, 
Table 3 Correlation coefficients for DXA measured whole body, total hip, and lumbar spine BMC, BMD, and calculated $B M A D ;$ QUS measured calcaneal BUA; and QCT measured vTBMD with age, nutritional status (height, weight, and $B M I$ ), disease severity ( $S K$ score), and lung function ( $F V C$ and $F E V$ ) parameters

\begin{tabular}{lllllllcc}
\hline & $\begin{array}{l}\text { Whole body } \\
\text { BMC }\end{array}$ & $\begin{array}{l}\text { Whole body } \\
\text { BMD }\end{array}$ & $\begin{array}{l}\text { Total hip } \\
\text { BMC }\end{array}$ & $\begin{array}{l}\text { Total hip } \\
\text { BMD }\end{array}$ & $\begin{array}{l}\text { L1-L4 } \\
\text { BMC }\end{array}$ & $\begin{array}{l}\text { L1-L4 } \\
\text { BMD }\end{array}$ & vTBMD & BUA \\
\hline Age & $0.89^{\star \star}$ & $0.80^{\star \star}$ & $0.82^{\star \star}$ & $0.77^{\star \star}$ & $0.87^{\star \star}$ & $0.81^{\star}$ & $0.47^{\star}$ & $0.47^{\star}$ \\
Height & $0.94^{\star \star}$ & $0.83^{\star \star}$ & $0.82^{\star \star}$ & $0.77^{\star \star}$ & $0.89^{\star \star}$ & $0.82^{\star \star}$ & $0.39^{\star}$ & $0.61^{\star \star}$ \\
Weight & $0.94^{\star \star}$ & $0.81^{\star \star}$ & $0.90^{\star \star}$ & $0.84^{\star \star}$ & $0.86^{\star \star}$ & $0.90^{\star \star}$ & $0.44^{\star}$ & $0.60^{\star \star}$ \\
BMI & $0.70^{\star \star}$ & $0.53^{\star \star}$ & $0.69^{\star \star}$ & $0.61^{\star \star}$ & $0.66^{\star \star}$ & $0.65^{\star \star}$ & 0.24 & $0.42^{\star}$ \\
SK score & -0.24 & -0.28 & -0.14 & -0.18 & -0.27 & -0.16 & $-0.50^{\star \star}$ & 0.00 \\
FEV & -0.19 & -0.27 & -0.18 & -0.25 & -0.25 & -0.14 & -0.31 & -0.02 \\
FVC & -0.08 & -0.10 & -0.05 & -0.10 & -0.15 & -0.03 & -0.18 & -0.01 \\
\hline
\end{tabular}

${ }^{\star} \mathrm{p}<0.05,{ }^{\star \star} \mathrm{p}<0.01$.

and vTBMD. The significant inverse relation between SK scores and vTBMD was unexpected.

\section{Discussion}

To the best of our knowledge, this is the first study in which DXA, QCT, and QUS have measured the bone status of CF children. We believe that such an approach permits a more comprehensive evaluation of factors that determine bone strength, namely the bone size (envelope), bone mass contained within the envelope, volumetric trabecular bone density, and bone structure, than if only one of these techniques was used. The majority of studies of bone mass and density measurements in CF children have been performed using DXA, which provides a measure of areal BMD that represents the integral (cortical and trabecular) amount of bone mineral within the bone envelope of the region of skeleton scanned divided by its projected bone area. As the depth, and therefore the volume of the scanned bone is not measured, areal BMD fails to distinguish between changes in mineral density and bone size in growing children. This is an important consideration, as chronic childhood illness, such as CF, might impair both growth and mineralisation of the skeleton. In order to minimise the influence of bone size on DXA measured $\mathrm{BMC}$ and $\mathrm{BMD}$, we recruited intentionally age, gender, pubertal stage, height, and weight matched controls for each CF subject ${ }^{14}$ from the local population. As it is not possible to recruit perfect size matched controls, we further adjusted the BMC at each site by taking into account the influence of bone area, height, and weight. ${ }^{32}$ The size adjusted whole body, lumbar spine, and total total hip BMC were not different in the $\mathrm{CF}$ and control groups.

At the lumbar spine, we also calculated the BMAD, by dividing the vertebral BMC by estimated volume $\left(\mathrm{BA}^{1.5}\right)$. The $\mathrm{BMAD}$ represents the estimated cortical and trabecular volumetric $\left(\mathrm{g} / \mathrm{cm}^{3}\right)$ bone density within the estimated envelope of the vertebral body. In the $\mathrm{CF}$ group, the mean estimated lumbar spine bone volume was non-significantly higher $(9.1 \%)$, whereas the BMAD was significantly lower $(8.3 \%)$ than in the control group. This suggests that in CF subjects there is an expansion of vertebral bone envelope that is not fully mineralised. However, the vTBMD, which was selectively estimated using QCT, was significantly higher in CF patients than in North American children. ${ }^{28}$ As about half of the total human vertebral body bone mineral content consists of cortical bone, ${ }^{33}$ our finding of normal total vertebral BMC, decreased BMAD, and higher vTBMD suggest that vertebral cortical thickness or density might be reduced in CF subjects. The mean calcaneal BUA, which reflects both density and structural properties of the bone, was not different in the two groups.

Taken together, our results suggest that the overall bone mineral content, density, and possibly bone structure of our CF patients was essentially normal, although the cortical thickness or density of the vertebrae might be decreased. Thus, contrary to our hypothesis, the main finding of our study was that bone mineralisation of our CF patients was essentially normal. These finding are similar to those of Salamoni and colleagues, ${ }^{14}$ who found that $\mathrm{BMC}$ was normal in well nourished children with $\mathrm{CF}$, compared with age, gender, and BMI matched controls. As the mean height SD scores of $\mathrm{CF}$ patients and controls were both about -0.5 (table 1 ), their bones are likely to be smaller relative to those of unselected population controls. Thus, it is likely that our CF patients have smaller, but normally mineralised, bones. This thesis is in keeping with the findings of Laursen and colleagues, ${ }^{6}$ who reported that the whole body BMC, adjusted for size using the method of Mølgaard and colleagues, ${ }^{34}$ was significantly increased in patients with CF under the age of 19 years, compared with controls. However, these subjects had significantly smaller and narrower bones, leading the authors to conclude that reduced bone size was an important factor for decreased bone mass in younger patients with CF. ${ }^{6}$

The recommended nutrient intake for dietary calcium was above the normal value for age in all but four CF subjects. This, together with normal serum concentration of PTH, $25-\mathrm{OHD}$, and $1,25(\mathrm{OH})_{2} \mathrm{D}$, suggests adequate calcium intake and absorption in the $\mathrm{CF}$ subjects. Inadequate intake or malabsorption of calcium and vitamin D deficiency would have resulted in secondary hyperparathyroidism. Our patients were more active compared to controls, although the median activity between the two groups was not significantly different. The lung function and median SK score of 81 (the higher the score the milder the disease, and vice versa) indicate that as a group, the CF patients in our study had relatively mild disease. Only three CF patients had been treated with a short course (less than four weeks) of oral corticosteroids. Thus, we believe that adequate intake of calcium, and normal 
vitamin $\mathrm{D}$ status in our physically active and less severely affected cohort of young CF children explains their normal overall bone mineral status. We are unable however to explain the negative relation between SK score and vTBMD SD score.

In summary, results of our study suggest that bone mineralisation, and possibly structure, were normal in our CF children. However, our results and conclusions only apply to relatively healthy and well nourished CF children. Our results also suggest that the maintenance of overall good health and nutritional status of $\mathrm{CF}$ subjects might allow normal bone mass acquisition and development of normal bone size and shape during childhood and adolescence. As fractures are an important secondary healthy problem in adolescents and adults with $\mathrm{CF}$, longitudinal measurements of bone size, shape, mass, and structural parameters during childhood, puberty, and advancing age are needed to understand the pathogenesis of bone fragility in subjects with this disease.

We are grateful to CF patients and schoolchildren who participated in this study. We thank Chrissie Alsop and Mel Hodgkinson for performing bone density scans, and Dr P Davis, of the University of Birmingham for statistical advice. We are also grateful to $\mathrm{Dr} M$ Hambleton for undertaking pubertal assessments in girls. This study was funded by the National Osteoporosis Society.

1 Dodge JA, Morison S, Lewis PA, et al. Cystic fibrosis in the United Kingdom 1968-1988. Paediatr Perinat Epidemiol 1993; 7:157-66.

2 Dodge JA, Morrison S, Lewis PA, et al. Incidence, population and survival of cystic fibrosis in the UK, 19681995. Arch Dis Child 1997;77:493-6.

3 Howarth CS, Freemont AJ, Webb AE, et al. A hip fracture and bone histomorphometry in cystic fibrosis. Eur Respir $f$ 1999;14:478-9.

4 Aris RM, Renner JB, Winders AD, et al. Increased rate of fracture and severe kyphosis: sequelae of living into adulthood with cystic fibrosis. Ann Int Med 1998;128:18693.

5 Henderson RC, Specter BB. Kyphosis and fractures in children and young adults with cystic fibrosis. $\mathcal{f}$ Pediatr 1994;125:208-12

6 Laursen EM, Molgaard C, Michaelsen KF, et al. Bone mineral status in 134 patients with cystic fibrosis. Arch Dis eral status in 134 pa

7 Bhudhikanok GS, Wang MC, Marcus R, et al. Bone acquisition and loss in children and adults with cystic fibrosis: a longitudinal study. F Pediatr 1998;133:18-27.

8 Baroncelli GI, De Luca F, Magazzu G, et al. Bone demineralization in cystic fibrosis: evidence of imbalance between bone formation and degradation. Pediatr Res 1997;41:397403.

9 Gardsell P, Johnell O, Nilsson B. The predictive value of bone loss for fragility fractures in women: a longitudinal study over 15 years. Calcif Tissue Int 1991;49:90-4.

10 Hahn TJ, Squires AE, Halstead LR, Strominger DB Reduced serum 25-hydroxyvitamin D concentration and disordered mineral metabolism in patients with cystic fibrosis. 7 Pediatr 1974;94:38-42.

11 Solomons NW, Wagonfeld JB, Rieger C, et al. Some biochemical indices of nutrition in treated cystic fibrosis patients. Am f Clin Nutr 1981;34:462-74.

12 Henderson RC, Madsen CD. Bone density in children and adolescents with cystic fibrosis. F Pediatr 1996;128:28-34.

13 Bhudhikanok GS, Lim J, Marcus R, et al. Correlates of osteopenia in patients with cystic fibrosis. Pediatrics 1996;97:103-11.

14 Salamoni F, Roulet M, Gudinchet F, et al. Bone mineral content in cystic fibrosis patients: correlation with fat free mass. Arch Dis Child 1997;74:314-18.

15 Gibbens DT, Gilsanz V, Boechat MI, et al. Osteopenia in cystic fibrosis. F Pediatr 1988;113:295-300.

16 Shaw N, Bedford C, Heaf D, et al. Osteopenia in adults with cystic fibrosis. Am f Med 1995;99:690-1.

17 Howarth CS, Selby PL, Webb AK, et al. Low bone mineral density in adults with cystic fibrosis. Thorax 1999;54: $961-7$.

18 Gluer CC, Wu CY, Genant HK. Broadband ultrasound attenuation signals depend on trabecular orientation: an in vitro study. Osteoporos Int 1993;3:185-91.

19 Hans D, Dargent-Molina P, Schott AM, et al. Ultrasonographic heel measurements to predict hip fracture in elderly women: the EPIDOS prospective study. Lancet 1996;348:511-14.

20 Cole TJ. Growth monitoring with the British 1990 growth reference. Arch Dis Child 1997;76:47-9.

21 Tanner JM. Growth at adolescence, 2nd edn. Oxford: Blackwell Scientific, 1962:28-39.

22 Duke PM, Litt IF, Gross RT. Adolescents' self assessment of sexual maturation. Pediatrics 1980;66:918-20.

23 Shwachman HL, Kulczycki L. Long term outcome of one hundred five patients with cystic fibrosis. Am $\mathcal{F}$ Dis Child 1958;96:6-15.

24 Anonymous. Guidelines for the measurement of respiratory function. Recommendations of the British Thoracic Society and the Association of Respiratory Technicians and Physiologists. Respir Med 1995;89:312-13.

25 Holland B, Welch AA, Unwin ID, et al. McCance \& Widdowson's Composition of Foods, 5 th edn. Cambridge: The Royal Society of Chemistry and Ministry of Agriculture, Fisheries and Foods, 1991.

26 Slemenda CW, Miller JZ, Hui SL, et al. Role of physical activity in the development of skeletal mass in children. $\mathcal{F}$ Bone Miner Res 1991;6:1227-33.

27 Carter DR, Bouxsein ML, Marcus R. New approaches for interpreting projected bone densitometry data. 7 Bone Miner Res 1992;7:137-45.

28 Gilsanz V, Roe TF, Mora S, et al. Changes in vertebral bone density in black and white girls during childhood and puberty. $N$ Engl f Med 1991;325:1597-9.

29 Mughal MZ, Langton CM, Utretch G, et al. Comparison between broadband ultrasound attenuation of the calcaneum and total bone mineral density in children. Acta Paediatr 1996;85:663-5.

30 Mughal MZ, Ward KA, Qayyum N, Langton CM. Assessment of bone status in children using the contact ultrasound bone analyser. Arch Dis Child 1997;76:535-7.

31 Iqbal SJ. Vitamin D metabolites and the clinical aspects of measuring metabolites. Ann Clin Biochem 1994;33:109-24.

32 Prentice A, Parsons TJ, Cole TJ. Uncritical use of bone mineral density in absorptiometry may lead to size-related artifacts in the identification of bone mineral determinants. Am 7 Clin Nutr 1994;60:837-42.

33 Faulkner KG, Gluer CC, Majumdar S, et al. Noninvasive measurements of bone mass, structure and strength: current methods and experimental techniques. Am f Radiol 1991;157:1229-37.

34 Mølgaard C, Thomsen BL, Prentice A, et al. Whole body bone mineral content in healthy children and adolescents. Arch Dis Child 1997;76:9-15. 